\title{
From transactional to a devoted relationship - toward performance-based service system governance
}

\author{
Ilmari Veijola \\ Aalto University, Siemens \\ ilmari.veijola@aalto.fi
}

\author{
Esko Hakanen \\ Aalto University \\ esko.hakanen@aalto.fi
}

\author{
Risto Rajala \\ Aalto University \\ risto.rajala@aalto.fi
}

\begin{abstract}
This field study explores a unique collaborative arrangement between two industrial firms, Siemens and Nestlé, presenting performance-based governance of the cooperation as means to mitigate the information asymmetry problem of the parties involved. In so doing, our field study depicts the essential activities in the formation of the IT-enabled and performance-based service system. Moreover, the findings delineate how technology-related changes affect manufacturing operations. The study contributes to the practice-based research on the emerging inter-organizational IS management issues by highlighting the role of parties' collaborative arrangements and interaction in the digital transformation of manufacturing operations.
\end{abstract}

Keywords: digital transformation, information asymmetry, interorganizational information system, service system, performance-based governance

\section{Performance-based contracting changes service system governance}

Recent developments in interorganizational systems and technologies have accelerated the emergence of digital service systems utilizing performance-based governance. The present study investigates how two industrial actors, Siemens and Nestlé jointly pursue the benefits that an interorganizational service system can bring to both parties. The cooperation between the case firms was established with a target of showcasing and validating the added business value that can be achieved with the implementation of digitalized service system. The system forms a comprehensive set of industrial digitalization solutions to a selected factory of Nestlé. In addition, Siemens provides the relevant lifecycle services that enables scaling up the validated solutions on a global scale to Nestlé operations. Our results show that, over time, the parties identified the need for establishing a collaborative service system driven by performance-based metrics, which was a novel cooperation business model for both case firms. We investigate their rationale for collaboration, the challenges that the formation of the new service system has brought with it, and the benefits that the parties seek through the co-development of the service system.

However, forming a collaborative service system for using information held by the service provider and the customer may cause insurmountable problems in producing shared value in industrial services. From the previous literature, we know about the IS-related challenges of interorganizational information systems and interorganizational collaboration [e.g., 6, 7], while the research of collaborative supply chain management [e.g., 13, 23, 25] has informed us about supply chain management-related challenges. Hence, practice-based research can improve the current understanding of the rationale for service system engagement, the essential activities in forming an interorganizational service system, and the means for creating value through collaborative information management in the service system.

Our study identifies four main types of activities mitigating information asymmetry in a service system; First, it reveals the actors' introspection, meaning the examination of one's own competences through selfreflection, identification of necessary complementary capabilities, and capability integration with the partner organization. Second, it requires an alignment of the collaborative activities with the selected partner, including the reconciliation of business rationales for the collaboration, cultural compatibility assessment, and stakeholder engagement. Third, the service system formation entails transformation of the governance practices, including technology affordance to seize the possibilities offered by the collaboration in relation to digital technology in the context of use, and platform orchestration to build a continuum for the IT solutions deployed for the collaboration, as well as systemic reconfiguration of the parties' collaborative arrangements. Finally, it involves scaling of the valuecreation potential of the systems in use, including the development of metrics for the essential KPIs, deliberation in the weighing of options and 
communication, and risk mitigation for overcoming the challenges related to developing disconnected solutions, and, conversely, in achieving synchronized and balanced way of creating value through the collaboration.

By studying the evolving practices of performance-based service system governance jointly developed by Siemens and Nestlé, our study contributes to the emerging research of the digital transformation of interorganizational cooperation. Our practice-based study discovers essential technologyrelated activities associated with forming an interorganizational service system. An analysis of the collaborative activities in the service system development adds value to the research that has previously looked interorganizational systems from the information systems development (ISD) perspective [e.g., 6, 14]. The present study opens a new page in industrial digitalization, which should consider the socio-technical change in IT-enabled service systems and their effects on value creation in manufacturing operations.

\section{Changes in service system governance call for system-level innovation}

Innovations take increasingly place in interorganizational settings, where participants concentrate their innovation efforts toward a joint target [18]. Because innovation is based on information sharing between participants, they are often shaped and even restricted by considerable information asymmetry. Our practice-based study of the collaboration between Siemens and Nestlé illustrates a potential solution, in which the parties jointly develop a system capable of sharing information between organizations, enabling the transparent measurement and use of performance as a basis for the cooperation.

\subsection{Information asymmetry slows down changes in business partnerships}

Information asymmetry is a condition under which one party of an undertaking possesses more information than the other party [3]. The foundation of the information asymmetry theory draws from the classical principal-agent problem of decision-making [9]. The essential premise of the theory is an agent suggesting an option possesses more information than the principal, who is forced to decide with limited or incomplete information $[3,24]$. The greater the information asymmetry between the parties, the more dependent they are on each other [1]. The transactional product-based exchange also allows a high degree of information asymmetry [2] because the resource integration is implemented through sequential transfer of often standardized artifacts and a minimal amount of new information.

When the parties transform toward a more finegrained allocation of tasks and responsibilities by service exchange, the situation gets more complicated, and the information asymmetry cannot be sustained. Information asymmetry has previously been studied in supply chain collaboration and IS development between business partners [e.g., 28]. When two companies jointly implement a service system, their knowledge endowments require harmonization. Thus, new relationship and contract types that focus on sharing the information and risks associated with a service agreement can help resolve the rigidities and opportunism associated with hidden or withheld information [3]. It has been suggested that reducing the asymmetry should increase alignment across organizations and limit the need for trusted intermediaries to convey the needed information between the actors, also affecting the appropriation of value among stakeholders [3].

\subsection{Inter-organizational information systems revolutionize service system governance}

Digital transformation of the manufacturing and technology industries has advanced service-based value creation in many product-focused companies and technology vendors [17]. Moving from traditional industrial services to IT-enabled remote diagnostics, control of industrial processes, and digitally administered information of industrial operations has given rise to autonomous solutions that enhance the context of service operations to managing increasingly complex service systems [21]. Also, digital technologies have expanded the possibilities for IT services, as the increased interconnectivity of objects enables new data-based services and solutions [5, 20]. Providing companies with more diverse and more cost-efficient access to data helps them improve their offerings or allow new parties to partake in the existing processes [15]. These changes have profoundly affected service systems, providing new means to enhance the interoperability and adjustability of operations and decision-making across organizational boundaries $[8,15]$.

Thus, development of inter-organizational information systems to support complex digital service systems call for careful alignment across the participating firms [11]. Collaboration in service system may enable performance improvements but are 
highly challenging to implement [4]. Hence, a transition toward service-based value creation can positively or negatively impact the firm performance. Adopting new service systems affects the configuration of the participating firms' resources, capabilities, routines, and structures. A failure to accomplish transformation in these aspects is likely to cause unfavorable service performance or financial losses [4]. While digital technologies provide access to detailed data on processes or related service agreements [19], the same data may be analyzed differently, with different preferences, goals, or interpretations. In the light of these considerations, it appears that the success of service systems depends on how well they succeed in reducing the harmful effects of information asymmetries.

\section{Empirical context}

Our field research examines the collaboration between two international companies, Siemens and Nestlé, which together develop a new collaboration model that includes performance-based IT services supporting the operations of the Nestlé-owned production unit. The initial discussions leading up to entering the cooperation between Siemens and Nestlé took place in 2017 between the top management of the collaborating firms. The customer (Nestlé) sought a strategic partner (and selected Siemens) to jointly analyze the performance of its Juuka factory.

The Juuka factory in Finland was selected as a brownfield showcase site for the performance-based IT service due to the existing factory control systems having reached the end of their lifecycle. Our longitudinal, field study includes interviews with experts and managers on both parties and observation of the operations in practice. This approach enabled collecting rich data in a real-life context [10]. The approach allows the use of multiple types of data about the collaboration between Nestlé and Siemens. In result, it was possible to obtain a comprehensive understanding of the context of the operations and the deep structures of the cooperation between the parties.

\subsection{Case description}

The first steps of the cooperation between Siemens and Nestlé included a complete modernization of the factory's production automation systems. The modernization was executed under a standard delivery project business model for creating a proper foundation for the upcoming journey of digital transformation. Nestlé's partnership with Siemens grew into a strategic alliance founded on a performance-based service system between the parties. The parties identified that the transparency of information on the development activities, and the need to share knowledge and observations about the experienced challenges in the collaboration, required a new approach to cooperation between the parties in the service system.

The parties agreed on the Juuka factory production efficiency [EUR/kg] as the main performance metric for the performance-based service system. Thus, at the outset of the process, the parties committed to a strategic partnership utilizing modern collaborative service design methods and a change from transactional to devoted relationship as some the key drivers for the cooperation. Regular "Value Hacker" co-creation sessions supported the continuous digital transformation journey. The sessions targeted primarily on enabling open and transparent knowledge exchange and ideation between all relevant stakeholders, making sure all organizational levels of the case firms and actors in the surrounding ecosystem participated regularly. It was promptly recognized that such continuous co-creation activities started to form the basis for a cultural alignment between the two companies, although that was not the initial target. Later, the alignment acted as an enabler for a wider scale organizational transformation and commitment within the companies.

\subsection{Data collection and analysis}

In the first phase of our empirical study, from Oct 2019 to April 2020, we conducted 16 interviews with managers and experts from the partner organizations. Also, we performed participant observation in the case, which enabled collecting field notes and obtain documents from the partner organizations to identify problems that the individual managers and experts in the case organizations experienced in their daily work. The empirical data was used to form an understanding of how the actors resolved their challenges by their new collaborative arrangement. Moreover, our empirical inquiry aimed to understand the rationale for establishing the service system that involved performance-based contracting of IT services in the Juuka factory. Also, we explored the obstacles that arose with developing the planned solutions to the problems experienced by the actors.

From late 2019 to mid-2021, we collected an extensive set of documentary information, including internal documents, memos, presentation material, correspondence, contracts, and plans with permission from the case firms to complement the analysis. 
Table 1 Data sources used in the analysis

\begin{tabular}{|c|c|c|}
\hline End-User interviews & Date & Duration (min) \\
\hline Factory Director & $1-10-2019$ & ca. $45(4)^{*}$ \\
\hline Production Manager & $1-10-2019$ & ca. $45(3)^{*}$ \\
\hline Quality Manager & $1-10-2019$ & ca. $45(7)^{*}$ \\
\hline Production foreman & $1-10-2019$ & ca. $45(5)^{*}$ \\
\hline Maintenance planner & $1-10-2019$ & ca.45(4)* \\
\hline Business Administrator & $1-10-2019$ & ca. $45(3)^{*}$ \\
\hline \multicolumn{3}{|l|}{ Supplier interviews } \\
\hline Director, Services & $24-3-2020$ & 89 \\
\hline Director, Projects & $24-3-2020$ & 83 \\
\hline Head of Service Design & $24-3-2020$ & 94 \\
\hline Director, Business Admin. & $14-4-2020$ & 85 \\
\hline Director, Factory Automation & $14-4-2020$ & 81 \\
\hline Chief Executive Officer & $14-4-2020$ & 91 \\
\hline Director, Sales & $15-4-2020$ & 88 \\
\hline Account Manager 1 & $15-4-2020$ & 84 \\
\hline Account Manager 2 & $15-4-2020$ & 89 \\
\hline Director, Business Dev. & $29-4-2020$ & 84 \\
\hline \multicolumn{3}{|l|}{ Documents (type) } \\
\hline Project memo & $8-11-2019$ & N.A. \\
\hline Project memo & $2-4-2020$ & N.A. \\
\hline Project memo & $16-6-2020$ & N.A. \\
\hline Project memo & $18-11-2020$ & N.A. \\
\hline Project memo & $6-5-2021$ & N.A. \\
\hline Project Co-Creation report & $31-8-2020$ & N.A. \\
\hline
\end{tabular}

*Total duration of the discussion (voice-recorded interview on the topic)

During the data collection phase, one of the researchers acted as a participant-observer within one of the case organizations, Siemens. The participantobserver maintained an ongoing collaboration with both case firms throughout this research project, monitoring the development of the service system and related solutions over time. The collection of empirical data included an active in-depth observation of the case and selection of documentary evidence, which helped the research team to develop an overarching understanding of the strategy and operations of the case.

The participant-observer produced memos detailing actual events in the development of the service system and the discussions surrounding significant decisions by the parties involved. Based on the observations, the researchers constructed a timeline of significant events and activities in the case. The timeline provided us with a processual view of the transformation that took place in the case toward an autonomous service system. As suggested earlier by Westbrook [26], the internal viewpoint proved instrumental in increasing the comprehensive understanding of the studied phenomenon, and it augmented the validity of the study. The participant observation enriched the research database with an extensive set of documentary evidence from the case organizations.

Based on the rich and heterogeneous dataset, the analysis focused on factual elements rather than subjective interpretations of the issues studied in the case. In particular, the investigation was centered on the structural changes and operational activities in the collaboration between Siemens and Nestlé after establishing their partnership. The analysis followed the principles of abductive reasoning, which includes constant comparison $[12,16]$ of observed instances and previous knowledge of the phenomenon. In the analysis, issues relevant to the study were identified and reflected in the light of the prior knowledge of socio-technical systems. The observations were structured into four main categories that delineated the identified patterns of the changes in the service system.

\section{Findings}

From the data gathered in the longitudinal quantitative case study, four main themes emerged as common challenges that the case companies aimed to increase their understanding of by entering into the performance-based service system. A summary of the findings and illustrative excerpts from the data are presented in Table 2 .

\subsection{Introspection mitigates risks related to technology feasibility}

Due to the assumption that already highly efficient and fine-tuned industrial processes would significantly benefit from the introduction of new digitalization technologies; Nestlé had identified a competence gap in state-of-the-art digitalization technologies: "We need a partner to scale up" Internal doc. (D) [N]. In turn, Siemens had multiple experiences in not being able to quantify its technological offering in terms of tangible business value due to a lack of information on its' customers' production processes and business: "We should be able to understand customer's business so accurately that we know how to create metrics [for value-based operations] ... So, the fact that this is so new approach to us all, and so different from the previous way of doing things that we may not know 
what to ask and the customer may not know how to answer." Account Manager 2 (I) [S]. Both had experienced the challenges and uncertainty in conducting business transactions with these competence gaps, which amounted to a natural driver for an open and transparent partnership between the firms to extend the knowledge capabilities required by the digital transformation on both sides.

While technology is a typical focal point in such a digitalization development journey, Nestlé had come across additional challenges during their previous development initiatives. Support was needed in managing the organizational and cooperative transformations, and converting the highly sophisticated technology solutions into tangible business value. In other words, while novel technology can be considered as an enabler in solving complex business challenges, such technological solutions are typically semi-automatic advisory systems and the limitations emerged from the shopfloor organization and capabilities required for utilizing such technologies: "We are like advisors for the customer." Director, Factory Automation (I) [S]

\section{Table 2 Data structure [S=Siemens; $N=$ Nestlé $]$}

\begin{tabular}{|c|c|c|}
\hline Categories & Subthemes & Excerpts from the data \\
\hline \multirow[t]{9}{*}{$\begin{array}{l}\text { 1. Intro- } \\
\text { spection }\end{array}$} & \multirow{3}{*}{$\begin{array}{l}1.1 \text { Compe- } \\
\text { tence (self) } \\
\text { reflection }\end{array}$} & $\begin{array}{l}\text { "First, it is difficult for the customer to know what it is buying and, second, what it is going to get" Director, } \\
\text { Services (I) [S] }\end{array}$ \\
\hline & & $\begin{array}{l}\text { "Working together is important already in the early stages [of problem-solving], and it helps all along the way } \\
\text { that there is a jointly defined direction, and that the direction is the same for both parties" Chief Executive } \\
\text { Officer (I) [S] }\end{array}$ \\
\hline & & $\begin{array}{l}\text { "In reality industrial actors do not have human resources to really look for new technologies on the market all the } \\
\text { time for driving efficiency. Then the companies that develop such technologies and invest in research and } \\
\text { development are very valuable interlocutors in this type of activity." Director, Sales (I) [S] }\end{array}$ \\
\hline & \multirow{3}{*}{$\begin{array}{l}1.2 \text { Identifi- } \\
\text { cation of } \\
\text { comple- } \\
\text { mentary } \\
\text { capabilities }\end{array}$} & $\begin{array}{l}\text { "We may have [a solution like] a Mercedes in use, but if we drive it like a Lada, we cannot make the most of it" } \\
\text { Factory Manager (I) [N] }\end{array}$ \\
\hline & & $\begin{array}{l}\text { "There is no doubt that capability building is critical in moving towards a digital factory. This is something we } \\
\text { should share with our senior stakeholders as a part of the success story" Internal doc. (D) [N] }\end{array}$ \\
\hline & & $\begin{array}{l}\text { "So, it is an entity where there is no chance that the customer will be able to resolve it. And even with us, not one } \\
\text { person can do it, but there is a network supporting our expert where a lot of different skills come together." - } \\
\text { Director, Factory Automation (I) [S] }\end{array}$ \\
\hline & \multirow[t]{3}{*}{$\begin{array}{l}1.3 \\
\text { Capability } \\
\text { integration }\end{array}$} & $\begin{array}{l}\text { "In a performance contract, it is possible to get into the customer's core business and see the drivers from the } \\
\text { customer vantage point and understand what is useful, which in turn allows us to create value for the customer as } \\
\text { efficiently as possible." Director, Business Administration (I) [S] }\end{array}$ \\
\hline & & $\begin{array}{l}\text { "I can confirm the statement on training. It was really, really, really good value add training. We are now far } \\
\text { more independent in fixing problems in reasonable time" - Internal doc. (D) [N] }\end{array}$ \\
\hline & & $\begin{array}{l}\text { "The customer's level of expertise and resourcing are perhaps leaner than in previous years and, as a result, } \\
\text { suppliers need to contribute even more to the co-development and co-creation." Account Manager } 1 \text { (I) [S] }\end{array}$ \\
\hline \multirow[t]{9}{*}{$\begin{array}{l}\text { 2. Align- } \\
\text { ment }\end{array}$} & \multirow[t]{3}{*}{$\begin{array}{l}\text { 2.1 Business } \\
\text { rationale }\end{array}$} & $\begin{array}{l}\text { "If the buyer does not know what to buy and the seller is not quite sure what to sell, then that is a very natural } \\
\text { point where the parties set out to strive together for what is the value that can be achieved through the } \\
\text { collaboration and co-development of the technology." Director, Services (I) [S] }\end{array}$ \\
\hline & & "We have to show indisputable savings" Internal doc. (D) [N] \\
\hline & & $\begin{array}{l}\text { "The world is full of good products, but a company can't stand out with products, and that's not really essential. } \\
\text { But in our clientele, products are not really of interest to anyone, but they are interested in how they can get their } \\
\text { own production run according to plan and at the lowest possible costs and risks. This leads to the fact that yes we } \\
\text { have to create the benefit and meaning through services and prove that it is not usually possible with products } \\
\text { alone." Director, Sales (I) [S] }\end{array}$ \\
\hline & \multirow[t]{3}{*}{$\begin{array}{l}2.2 \text { Cultural } \\
\text { compatibility }\end{array}$} & $\begin{array}{l}\text { "I want to see fast and furious execution of tangible results. Direct and open cooperation and communication } \\
\text { have helped a lot" Internal doc. (D) [N] }\end{array}$ \\
\hline & & "One of the highlights is the good and measurable results from the Value Hacker sprints" - Internal doc. (D) [N] \\
\hline & & $\begin{array}{l}\text { "The value-based business model seems to bring the supplier and the customer closer together" Internal doc. [D] } \\
\text { [S] }\end{array}$ \\
\hline & \multirow{3}{*}{$\begin{array}{l}.3 \\
\text { Stakeholder } \\
\text { engagement }\end{array}$} & $\begin{array}{l}\text { "Nestle's top executives talk to each other, so here the cooperation is, as they say, more diverse and, on several } \\
\text { different levels then, at the stage when we have such an agreement." Director, Business Administration (I) [S] }\end{array}$ \\
\hline & & $\begin{array}{l}\text { "Production plants do not have much of their own expertise. But they have know-how in different sites across } \\
\text { Europe, but it doesn't show up there in the factory's day-to-day operations. So, that environment is pretty } \\
\text { complicated too, if you look at Nestlé because it is a big company, so it's important who you talk to and who has } \\
\text { that understanding." - Director, Factory Automation (I) [S] }\end{array}$ \\
\hline & & $\begin{array}{l}\text { "But you have to manage that whole network you don't; you have to be able to talk to the factory manager, the } \\
\text { production managers and also the people who do it there at floor level. That's how I would say it. One should get } \\
\text { that big picture and have to be able to talk to people of different levels." - Director, Factory Automation (I) [S] }\end{array}$ \\
\hline $\begin{array}{l}\text { 3. Transfor- } \\
\text { mation }\end{array}$ & & $\begin{array}{l}\text { "The impetus has, of course, been the growth of digitalization and, in particular, the reflection on its benefits." } \\
\text { Director, Business Administration (I) [S] }\end{array}$ \\
\hline
\end{tabular}




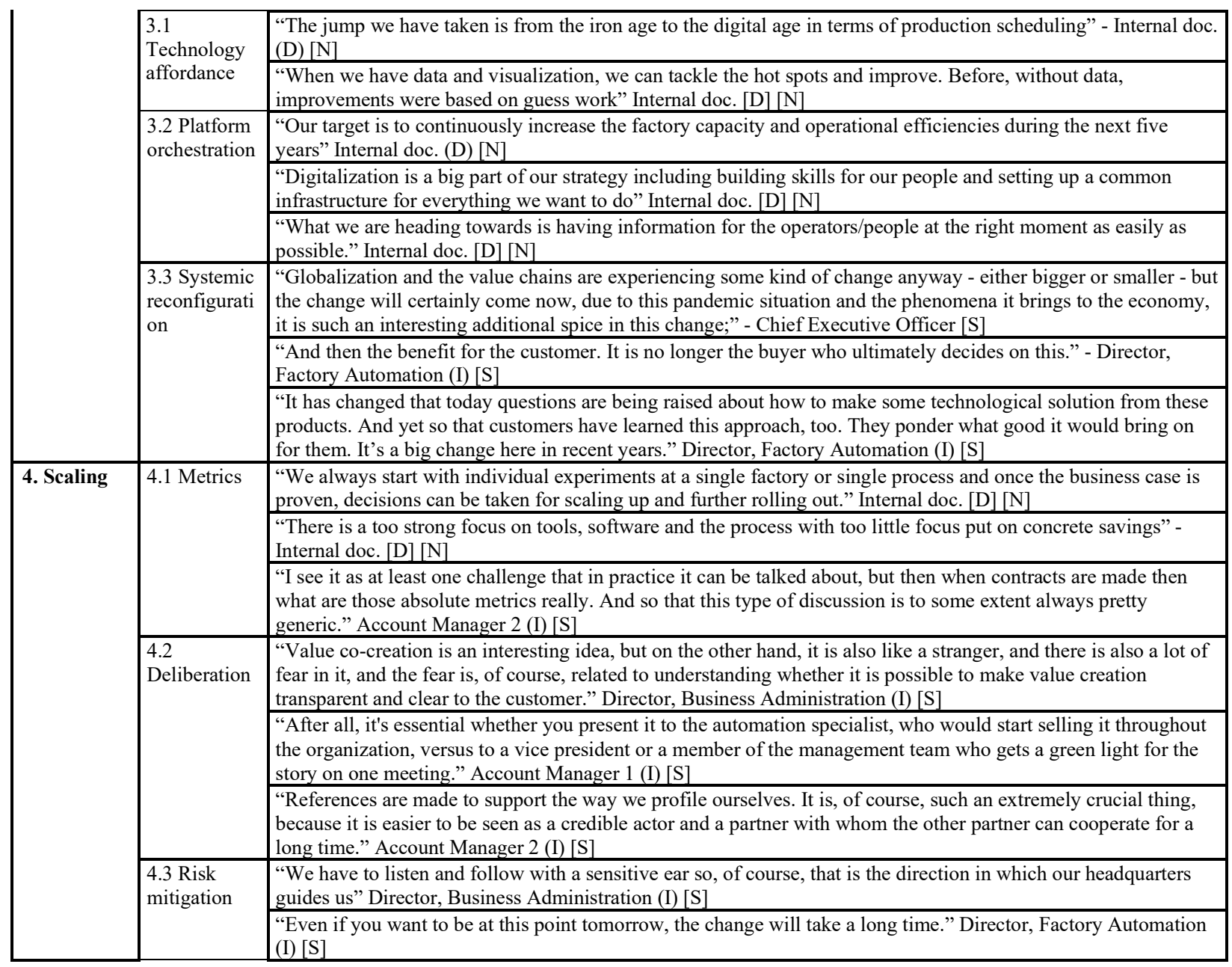

The internal transformation of Siemens from a product- and technology-centric organization into a solution- and value-driven one has required an organizational transformation and new competencies. The so-called T-shaped competence profile requirement from many of its existing employees plays a critical role in translating complex technology innovations into added customer business value. Consequently, Siemens has shifted its focus from a technology-oriented sales organization into a service and added value oriented one. The "Value Hacker" cocreation initiative was launched, aiming to create open dialogue and ideation between Siemens and its industrial customers in a variety of domains, thus improving the competencies of the actors involved.

\subsection{Alignment of business rationales and cultural conformance shapes the governance}

The cooperation between the case companies started to transform into a partnership on a strategical level. Key factors were the capability requirements of both actors in the service system, as well as the trust and transparency requirements needed to achieve the required common capabilities. The parties begun to recognize common targets in the digital transformation journey in terms of added business value rather than in terms of project stages or milestones: "In the past, we talked most of the time about products and today most of the time we discuss about benefits and meanings, so that has been perhaps the biggest change in all of this." Director, Sales (I) [S]. Such discussions were driven by plant performance and required alignment among all involved actors on what is perceived as valuable for certain business operations. To meet this need, significant emphasis in the development of the service system was put on applicable, indisputable, and reliable metrics for quantifying the generated business value throughout the cooperation.

It was, however, inevitable that the cultural aspects from both of the giant organizations played a significant role. Different cultures shaped the strategic partnership and the cooperation for achieving the 
jointly defined targets; "After all, you have no choice but to have to adapt to that different culture" Director, Business Administration (I) [S]. Regular and open information exchange through the continuous cocreation activities have been some of the key activities in merging the organizational cultures closer to one another and shifting the mindset orientations of relevant actors towards a common direction and target. Both case companies had identified such experiences as valuable for efficiently driving cooperation activities with external partners in the future.

Digital transformation is commonly a top-level strategic priority for most industrial manufacturing entities. Hence, the advancement of such activities is usually driven by the top operative management of these companies rather than, e.g., by purchasing or supply chain management organizations. The same applies in many instances to the supplier's activities in terms of promoting such technologies. "It is an extremely complicated situation for their purchasing function as well when it is a new thing for which there is no operating model, and they are not able to create their own basic way of working for the purchasing organization, which then often escalates to top management just like within our organization, too. It brings on its own challenges. " Account Manager 2 (I) [S]. These realities can present a challenge in effective stakeholder engagement and management, which are required for the success of any development initiative, let alone a comprehensive digital transformation of an end-to-end factory production line or an organization. "So, within the customer organization, there is a wide network of contacts that need to be mastered." Director, Factory Automation (I) [S].

Nestlé and Siemens made the decision early on in their journey to involve all the relevant stakeholders in a layered structure for the service system governance. This decision allowed all of the relevant stakeholders from both organizations to monitor and contribute to the performance of the service system. While such governance on all organizational levels might appear complex and time consuming, it has been identified by the case companies as a necessity in order to carry the long-term cooperation effectively and successfully. This has allowed the parties to adjust the service system focus and direction of the cooperation in an agile manner while the ever-changing business landscape and global trends around the operations of these companies shift as well; "The governance model of the contract has been working and providing the implementation team with important focus and guidance" Internal doc. (D) [S]

\subsection{Transformation of governance is a long- lasting journey}

From day one, the case companies cooperated to adopt and implement the most relevant modern digital technologies and solutions for Nestlé's production site in Juuka in order to improve production efficiency. It was apparent from the data that there was a clear sense of urgency on both sides to get tangible benefits of the digital service system. In many cases, identifying and committing to such technological solutions at an early stage of the cooperation may be more complex than it sounds. The case companies chose to focus the performance-based principles of the service system in their decisions on technological solutions.

When setting up the service system, Siemens and Nestlé had to aim for reaching continuously evolving targets. Such a challenge may be typical in industrial digital transformation projects. Yet, it is drastically different from the nature of traditional industrial investment projects, which include a somewhat clear timeline, scope, specifications, and obligations pertaining to all involved parties. Siemens' approach to this challenge indicated that modern technology platforms within a scalable system architecture provide versatile tools, which can be applied to various different types of business use cases. This vision has materialized at the Juuka factory in terms of utilizing IoT data for identifying new business potential in the factory processes. The structured data resides on a platform-based IoT solution, which is open and versatile enough to support the development various business cases, created in the ideation and co-creations sessions of the service system. Furthermore, while the platform-based data has been utilized in improving the service system performance metrics, the data has been valuable for measuring and validating the improvement in said performance metrics. Over time, the Siemens and Netstlé's strategic partnership has evolved into a performance-based, data-driven service system, which combines performance metrics to open and collaborative co-creation sessions.

Our data showed that both case companies had identified an ongoing transformation within the strongly rooted status quo of industrial business operations and transactions. Thus, the showcase between the parties was also intended to validate or disregard certain paths of future industrial business-tobusiness transactions: "Several clients have pointed out that these types of issues (value-based business models) should be discussed." Account Manager 2 (I) $[S]$. The interviewees regarded the case at hand as one of the most innovative business models introduced to the mainstream core business operations on both sides. While some of the elements of the performance-based service system have been more successful than others, both case companies has regarded the experience as eye opening. Especially, the firms were surprised by 
the value that can be created by simply establishing trust and incentivizing actions among relevant stakeholders towards a common target.

\subsection{Scaling requires viable metrics and joint forethought}

One of the key findings in this study was the strong emphasis that the novel performance-based business model puts into the realization of tangible benefits that can be measured and validated. While both parties had acknowledged the applied business model ambitious and challenging, the case service system changed the mindset of the case companies on how efficient scaling up can be executed in terms of industrial digitalization solutions: "It is great that through the cooperation and the new instrumentation we are able to generate and validate savings" Internal doc. (D) [N]. The cooperative efforts put into measuring generated operational savings and even added production capacity. Without the performance metrics created in the first stages of the cooperation, new investment decisions and the continuity of ongoing development initiatives might have been impossible. The lack of metrics might have become obstacles that slow down or, in the worst case, prevent the utilization of similar digitalization technologies on a global scale. The data driven co-creation and validation of jointly achieved successes has played a significant role in allowing similar solutions to be implemented by both companies in other areas of their business or industry. "Now we are moving to exactly the right direction with indisputable savings. Scale up learnings from Juuka to other Nestlé factories" Internal doc. (D) [N]

Of course, both of the case firms have a vested interest in communicating success stories in the field of industrial digitalization within their own organizations as well as externally for strategic purposes. In order to conduct such communication strategy effectively, tangible results in terms of measurable business results have been immensely valuable. Such arguments on value allow both parties to separate themselves from the variety of technologyfocused solutions in the field of industrial digitalization by articulating the meaning and urgency of digital transformation within the industry sector. Many interviewees in the study conveyed a general feeling that the days of technology-focused communication are coming to an end. In the future, tangible value arguments need to be present in all communications activities to stand out. Thus, the experiences and value arguments from the Juuka factory have been valuable assets for both in terms of scaling up these experiences and in developing similar service systems.
Some of the cooperative development initiatives between the case companies seemed more valuable for improving the production efficiency of the Juuka factory than others. While both parties were geared for success, the mindset of retaining a certain level of risk and accepting failures within certain preconditions was clear in the minds of the case companies ever since the initiation of the service system. For example, the parties adopted a 'fail-fast' mentality throughout the cooperation. Such mentality was considered a necessity for the performance-based cooperation model and for conducing multiple, complex technological development projects in parallel, without the clarity of a scope and time schedule of a traditional investment project. The collaborative and agile way of working provided a solid foundation for related risk mitigation. The 'fail-fast' culture and mindset was applied to all areas of the service system cooperation, from technological implementation to the commercial frameworks and limitations in the performance-based contract between the parties. According to the parties, this type of risk-management model, in combination with the service system governance model, has proved to be an efficient methodology of advancing the digital transformation and its business-related targets towards the right direction, while retaining an acceptable level of business risk.

\section{Discussion}

Our study analyses how two industrial firms Siemens and Nestlé pursued to mitigate an information asymmetry problem by forming a collaborative service system, ultimately aiming at improving the production efficiency of Nestlé's factory in Juuka. Their service system provided an exciting vantage point to analyzing how industrial actors can establish an interorganizational collaborative arrangement, embodying a comprehensive digital transformation of the factory production systems and operation. This new cooperative arrangement represents a service system in which the partners have committed to a long-term digital transformation partnership utilizing a novel performance-based business model for financing the cooperation. Our analysis of the case sheds new light on the practical challenges associated with performance-based governance of collaboration in service systems. 


\subsection{Research implications}

The present study sheds new light on how an interorganizational service system may reduce information asymmetry between cooperation partners. Previous management research has applied the information asymmetry theory to identify and resolve challenges in transactions or contracts in collaborative settings [3]. Also, the theory has been widely used to explain situations where at least one party can enforce or effectively retaliate against certain parts of a collaborative arrangement. The problems studied from the information asymmetry perspective include cases in which other parties suffer from the selfish behavior of one party. This perspective is particularly relevant for the study of service systems [cf. 24] where the customer may have more information on the contingency factors of the service, while the service provider may be more knowledgeable of the technical solutions developed to carry out the service [27]. Schmidt and Keil [22] have suggested that private information asymmetry within firms may influence daily business activities. For example, firms with a more concrete understanding of their resources can use this information to gauge their advantage over competitors [22]. Our findings emphasize that while contractual agreements are often linear and do not adjust to changes in circumstances, a performancebased service system governance may adapt to contingency factors [24].

Four essential activities surface in our analysis in the formation of a service system. First, introspection signifies the importance of recognizing the actor's existing competencies and needs for capabilities beyond their organization and the ways of ensuring an efficient integration of identified capabilities. Second, alignment includes the efforts to unify the parties' meaning-making behind the collaboration in the service system for rationalizing the development activities and taking the business imperatives into account, ensuring the cultural conformity within the service system, and justifying the governance of the service system for effective stakeholder engagement. Third, transformation conveys the perspective of current technology affordance opportunities combined with technology platform reliant system architecture development for effectively managing the emerging digital transformation as well as the systemic reconfiguration of the collaborative arrangements between the actors. Finally, scaling is about validating the performance achieved within the service system in relation to the joint IS development, and deliberation on the most effective strategy for expanding similar service system activities towards other existing business operations. Also, balancing risk tolerance is crucial to allow larger-scale practical operations based on the service system.

\subsection{Managerial implications}

The case study allowed us to delineate the challenges and essential activities for establishing a performance-based service system to effectively drive digital transformation of an industrial manufacturing entity. To ensure value creation within such a service system, based on the findings of this empirical case, 1) the relevant actors should emphasize facilitating transparent capability integration through shared resources and culture as well as setting up an applicable framework for the case actors to collaborate and govern the service system on all relevant organizational levels. Also, 2) transformation of the cooperation into a strategic partnership has long-haul effects on the governance of the service. That is, it can increase the value of the business relationship for all parties involved.

Another aspect to consider when establishing such collaborative arrangements is that the chosen approach to IT development has to allow the continuous nature of digital transformation activities to fluently occur while ensuring that the service system actors are incentivized to contribute towards commonly recognized measurable business targets. Hence, 3) validation of the business value of digitalization development activities can, at best, lead to organized scaling up of the activities experimented in the collaboration. Such an effective scale-up procedure can 4) multilply the value creation potential with relatively limited risk. In summary, the aspects of performance-based service system governance listed above delineate some of the key elements of the collaborative arrangements between Siemens and Nestlé in the Juuka factory operations.

\section{Limitations and further research}

While our study provides a new perspective of performance-based governance of a service system between industrial partners, it is not free from limitations. Our findings are based on a single-case setting, focusing on a brownfield showcase between two partners in a single location. We acknowledge that studies on performance-based contracts in other industries may provide complementary insights. Thus, further studies are needed to increase the generalizability of our insights. For example, a study addressing greenfield settings might provide important knowledge on the service system development.

The joint initiative between the two parties exemplified how the created value may be more 
appropriately shared among the partners, when effectively using the data generated and accumulated from the production system. We call for future research addressing the impact of contextual environment. Also, it would be interesting to learn how partners in the service system may react to external changes and new opportunities.

\section{References}

[1] Aarikka-Stenroos, L., and E. Jaakkola, "Value cocreation in knowledge intensive business services: A dyadic perspective on the joint problem solving process", Industrial Marketing Management 41(1), 2012, pp. 15-26.

[2] Baldwin, C.Y., and C.J. Woodard, "The Architechture of Platforms: A Unified View", In A. Gawer, ed., Platforms, Markets and Innovation. Edward Elgar, Cheltenham, UK, 2009, 19-44.

[3] Bergh, D.D., D.J. Ketchen, I. Orlandi, P.P. Heugens, and B.K. Boyd, "Information asymmetry in management research: Past accomplishments and future opportunities", Journal of Management 45(1), 2019, pp. 122-158.

[4] Brax, S.A., A. Calabrese, N. Levialdi Ghiron, L. Tiburzi, and C. Grönroos, "Explaining the servitization paradox: A configurational theory and a performance measurement framework", International Journal of Operations \& Production Management(forthcoming), 2021.

[5] Cenamor, J., D. Rönnberg Sjödin, and V. Parida, "Adopting a platform approach in servitization: Leveraging the value of digitalization", International Journal of Production Economics 192, 2017, pp. 54-65.

[6] Chatterjee, D., and T. Ravichandran, "Governance of interorganizational information systems: A resource dependence perspective", Information Systems Research 24(2), 2013, pp. 261-278.

[7] Cho, B., S.Y. Ryoo, and K.K. Kim, "Interorganizational dependence, information transparency in interorganizational information systems, and supply chain performance", European Journal of Information Systems 26(2), 2017, pp. 185-205.

[8] Coreynen, W., P. Matthyssens, and W. Van Bockhaven, "Boosting servitization through digitization: Pathways and dynamic resource configurations for manufacturers", Industrial Marketing Management 60, 2017, pp. 42-53.

[9] Eisenhardt, K.M., "Agency theory: An assessment and review", Academy of Management Review 14(1), 1989, pp. 57-74.

[10] Eisenhardt, K.M., and M.E. Graebner, "Theory building from cases: Opportunities and challenges", Academy of Management Journal 50(1), 2007, pp. 25-32.

[11] Gao, S., E. Hakanen, and R. Rajala, "Digital transformation: The interplay of explorative and exploitative capability development", Proceedings of the 53rd Hawaii International Conference on System Sciences, (2020), 4306-4315.

[12] Glaser, B.G., and A.L. Strauss, "Discovery of substantive theory: A basic strategy underlying qualitative research", American Behavioral Scientist 8(6), 1965, pp. 5-12.

[13] Holland, C.P., "Cooperative supply chain management: the impact of interorganizational information systems", Journal of Strategic Information Systems 4(2), 1995, pp. 117-133.

[14] Kamp, B., and G. Parry, "Servitization and advanced business services as levers for competitiveness", Industrial Marketing Management 60, 2017, pp. 11-16.

[15] Ketokivi, M., and T. Choi, "Renaissance of case research as a scientific method", Journal of Operations Management 32(5), 2014, pp. 232-240.

[16] Kohtamäki, M., V. Parida, P. Oghazi, H. Gebauer, and T. Baines, "Digital servitization business models in ecosystems: A theory of the firm", Journal of Business Research 104, 2019, pp. 380-392.

[17] Nambisan, S., K. Lyytinen, and Y. Yoo, "Digital innovation: Towards a transdisciplinary perspective", In S. Nambisan, K. Lyytinen and Y. Yoo, eds., Handbook of Digital Innovation. Edward Elgar Publishing Limited, Cheltenham, UK, 2020, 2-12.

[18] Opresnik, D., and M. Taisch, "The value of big data in servitization", International Journal of Production Economics 165, 2015, pp. 174-184.

[19] Porter, M.E., and J.E. Heppelmann, "How smart, connected products are transforming competition", Harvard Business Review 92(11), 2014, pp. 64-88.

[20] Reim, W., D. Sjödin, and V. Parida, "Mitigating adverse customer behaviour for product-service system provision: An agency theory perspective", Industrial Marketing Management 74, 2018, pp. 150-161.

[21] Schmidt, J., and T. Keil, "What makes a resource valuable? Identifying the drivers of firm-idiosyncratic resource value", Academy of Management Review 38(2), 2013, pp. 206-228.

[22] Soosay, C.A., and P. Hyland, "A decade of supply chain collaboration and directions for future research", Supply Chain Management 20(6), 2015, pp. 613-630.

[23] Stiglitz, J.E., "Information and the change in the paradigm in economics", American Economic Review 92(3), 2002, pp. 460-501.

[24] Tong, P.Y., and J.L. Crosno, "Are information asymmetry and sharing good, bad, or context dependent? A meta-analytic review", Industrial Marketing Management 56, 2016, pp. 167-180.

[25] Westbrook, R., "Action research: A new paradigm for research in production and operations management", International Journal of Operations and Production Management 15(12), 1995, pp. 6-20.

[26] Winter, S., N. Berente, J. Howison, and B. Butler, "Beyond the organizational 'container': Conceptualizing 21 st century sociotechnical work", Information and Organization 24(4), 2014, pp. 250-269.

[27] Xie, W., Z. Jiang, Y. Zhao, and X. Shao, "Contract design for cooperative product service system with information asymmetry", International Journal of Production Research 52(6), 2014, pp. 1658-1680.

[28] Zhang, T., J. Luo, C.Y. Zhang, and C.K.M. Lee, "The joint effects of information and communication technology development and intercultural miscommunication on international trade: Evidence from China and its trading partners", Industrial Marketing Management 89, 2020, pp. 40-49. 